\title{
Adoption and intensity of adoption of beekeeping technology by farmers: The case of Sheko Woreda of Bench-Maji Zone, South West Ethiopia
}

\author{
Asfaw Albore $^{1}$, Dessalegn Anshiso ${ }^{1}$ and Getachew Abraham ${ }^{2}$ \\ ${ }^{1}$ Department of Agricultural Economics, College of Agriculture \& Natural Resources, Mizan-Tepi University \\ ${ }^{2}$ Department of Animal Science, College of Agricultural Sciences, Arba-Minch University \\ E-mail: gechoabraham@gmail.com
}

Received: 28.08.2019. Accepted: 28.09.2019

\begin{abstract}
Beekeeping delivers the rural people with sources of income, dietary use, pollination service and social benefit. In spite of the benefits obtained from beekeeping, farmer's resistivity to adopt the recommended modern beekeeping technological components (packages) is among the major problem. Therefore, the objectives of this study were to examine the intensity of adoption of beekeeping technology package, and identify factors influencing adoption and intensity of adoption of beekeeping technology package in Sheko district. Stratified sampling procedure was used to select sample households. A total of 200 household heads were selected randomly from adopters and non-adopters categories of four potential beekeeping localities. Date was collected by using household survey and key informant interview and analyzed by using censured Tobit model. From sampled households $68 \%$ of respondents who have bee hive; the majority of them fall under medium adopters' category. Variations in intensity of adoption of bee hive components were observed among adopter category. The output of censured Tobit model was indicate that six variables such as total livestock unit, apiary site visit by farmer, perceived cost of technology by farmer, distance of market center from home, knowledge of farmers for bee management and availability of bee hive technology were found to have significant influence on adoption and intensity of adoption of bee hive technological package. Therefore, agricultural policy and development interventions should give emphasis to the improvement of institutional support system so as to achieve wider adoption and intensity of adoption for small scale farmers.
\end{abstract}

Keywords: Adopters; Livestock unit; Non-adopters; Tobit model

\section{Introduction}

Beekeeping is an integral component in agricultural economy of developing countries and produce much more than food, since it contribute to the income, nutrition (dietary use), natural resource conservation, pollination service and social benefit. It is a sustainable form of agriculture which is beneficial to the environment and endows economic reasons for the retention of native habitats and potentially increase yield from food and other forage crops (Jones, 1999). It is believed to play a significant role and one of the possible options to the smallholder farmers in order to sustain their livelihood.

Africa produces $11 \%$ of the total world honey (Akanbi, 1994). Recent survey has confirmed Ethiopia tremendous potentials in beekeeping, ever since its honey fauna being so rich coupled with a sustainable climate for beekeeping. Ethiopia has been amongst the principal honey and beeswax producers worldwide for centuries. It is estimated that the country has the potential to produce 500,000 tons of honey per year, However, the Current production is less than $10 \%$ of its estimated potential (Moard, 2007).

Ethiopia is the leading producer of honey and beeswax in Africa. The country produces about 43,373 metric tons of crude honey per year, thus shares $23.5 \%$ of Africa and $2.35 \%$ of world's honey production. This makes the country rank first in Africa and 10th in the world (AMP, 2007). The ideal climatic conditions and diversity of bee floral allow the country to sustain around 10 million honeybee colonies, of which 7 million are kept in local beehives by farmers and the 
remaining, exist in the forests as wild colonies. This makes the country to have the highest bee density in Africa (Nuru, 2002).

Despite the long tradition of beekeeping in Ethiopia, the share of the sub-sector in the GDP has never been commensurate with the huge potentiality of the country. The productivity has always been low, leading to low utilization of hive products domestically, and relatively low export earnings. Thus, the beekeepers in particular and the country in general are not benefiting from the sub sector (Nuru, 2002).

The crusade to adopt modern techniques in beekeeping has not received adequate attention by Ethiopian government though a major objective of its policy strategy is to decline poverty of small-scale farmers through provision of researchgenerated knowledge and technologies. Technical information is very important in any sphere of agricultural development programs. Hence, clear understanding about program related information like socio-economic condition of target groups and identifying the factors that affect the information utilization pattern has paramount importance for appropriate implementation of the program. In this respect, there are no available records on honey production or consumption trends in south west part of Ethiopia.

In the study area, there is lack of empirical evidence \& related information on factor affecting adoption and intensity of adoption of honey producing farmers'. However, some empirical studies conducted in other areas indicated that utilization of information vary from place to place and also that there are many factors like personal, institutional, sociopsychological, situational and economic which affect its effective and efficient utilization (Asres, 2005). It is therefore, in responding to the above identified gap that this research was conducted in Sheko Woreda of Bench Maji zone. Hence, the overall objectives of this study were to examine the intensity of adoption of beekeeping technology; and to determine factors affecting adoption and intensity of adoption of beekeeping technologies.

\section{Research Methodology}

\section{Description of the study area}

Sheko Woreda is among the 10 Woredas of Bench-Maji zone. It is bordered by North Bench Woreda in North, Yeki woreda of Shaka zone in the West, Guraferda in South West and South Bench in East. The Woreda is located at $695^{\circ}$ $715^{0} \mathrm{~N}$ latitude and $35.29-35.61^{0} \mathrm{E}$ of longitude. It is situated $579 \mathrm{~km}$ south of Addis Ababa and about $835 \mathrm{~km}$ of SNNPR of capital city Hawassa. The average annual temperature of Sheko Woreda is $23^{\circ} \mathrm{C}-250^{\circ} \mathrm{C}$, the average rain fall $1500-$ $1800 \mathrm{~mm}$ and it has $55 \%$ Weinadega, $15 \%$ Dega and 30\% Kola agro-climate zone. The total population of Sheko Woreda is 51,195 among this 25349 ( $49.5 \%)$ are female and 28854 (50.5\%) are male and has 22 Kebele administration. The livelihood of the farmers in Sheko Woreda is mainly established in and around the forests. Mixed farming is common type of farming system. Another source of income is beekeeping, which along with some cash crops (coffee \& spice) finds their way via traders to the administrative center of the Zone, Mizan Aman (BOA, 2013).

\section{Sampling technique}

In this study, first the potential bee keeping kebeles were identified for selecting sample respondents. Accordingly, from the total of 22 kebeles, six were known with huge potential for honey bee production. Since this study was focused on bee keeping, the sample kebeles were potential bee keeping kebeles. Then, four kebeles from the six of potential beekeeping kebeles were randomly taken for selecting sample households. At next stage, households in the sample kebeles were stratified in two groups (adopters and non-adopters) of honey bee hive. Lastly, random sampling was used to select a total of 200 sample respondents from the four Kebeles based on proportional to size of the households.

\section{Method of data collection}

Both primary and secondary data were used to collect data on honey bee production pattern. A household survey method was carried out to collect primary data on personal, socio-economic, institutional, and psychological variables as well as on farm characteristics. Key informants interview (which includes model farmers, elders, and development agents) was also conducted to get further information on, particularly, the history of honey bee in the study area, modes of farmers organizations interaction with reference to honey production and also socio-economic and cultural intricacies that could potentially relate to adoption behavior of farmers. Secondary data was obtained from officials working in various GOs, and NGOs found in the Woreda. 


\section{Data analysis}

The data was analyzed using descriptive statistics as well as an econometric model. Intensity of adoption was seen through four categories of adopters' i.e. non-adopter, low, medium, and high adopters. The categories were tested if differences appeared for each of the honey bee components taken into consideration (Table 1).

Accordingly, adoption is a decision to make full use of an innovation at best appropriate course of action available (Rogers, 1983). For multiple practices (package), there are two options of measuring adoption; (i) adoption index: measures the extent of adoption at the time of the survey or (ii) adoption quotient: measures the degree or extent of use with reference to the optimum possible without taking time into consideration. In this study, the first option was employed. Accordingly, adoption index which shows to what extent the respondent farmer has adopted the whole set of practice was calculated using the following formula.

Where:

$\mathrm{AI}_{\mathrm{i}}=\frac{\sum_{\mathrm{j}=1, \mathrm{i}=1}^{\mathrm{m}, \mathrm{n}}\left(\frac{\text { smokadscoreji }}{\text { SMOKADOMAXj }}+\frac{\text { topbradscorejii }}{\text { TOPBRADOMAXjj }}+\frac{\text { spryradscoreji }}{\text { SPRYRADOMAXjj }}+\ldots .+\frac{\text { quenexcadscoreji }}{\text { QUENEXCADOMAXj }}\right)}{\mathrm{NP}}$

AIi=Adoption index of the ith farmer

$\mathrm{i}=1,2,3, \mathrm{n}$, and $\mathrm{n}=$ total number of respondents

$j=1,2,3, m$, and $m=$ total number of major components of the honey bee producing technology components.

Table 1. Technological components shows adoption index or extent of the respondents.

\begin{tabular}{llll}
\hline $\mathbf{N}$ & Variables & $\begin{array}{l}\text { Variable abbreviation of adoption } \\
\text { score of ith farmer }\end{array}$ & $\begin{array}{l}\text { Variable abbreviation of maximu } \\
\text { m potential score of adoption }\end{array}$ \\
1 & Smoker & Smokadscoreji & SMOKADOMAXj \\
2 & Top bar hive & Topbradscoreji & TOPBRADOMAXj \\
3 & Water sprayer & Spryradscoreji & SPRYRADOMAXj \\
4 & Protective cloth & Proclthadscoreji & PROCLTHADOMAXj \\
5 & Hive stand & Hvestndadscoreji & HVESTNDADOMAXj \\
6 & Langstroth & Lnsthadscoreji & LNSTHADOMAXj \\
7 & Bee brush & Brushadscoreji & BRUSHADOMAXj \\
8 & Honey extractor & Hyextradscoreji & HYEXTRADOMAXj \\
9 & Feeding WITH SYRUP & Syrupadscoreji & SYRUPADOMAXj \\
10 & Foundation sheet & Founsheetadscoreji & FOUNSHEETADOMAXj \\
11 & Queen cage & Quencgeadscoreji & QUENCGEADOMAXj \\
12 & Queen excluder & Quenexcadscoreji & QUENEXCADOMAXj \\
\hline
\end{tabular}

In this study, beekeeping technology component, which has been promoted in the country, consists of twelve components. The honey bee producing technology component were, always use of smoker, always use of top bar hive, always use of water sprayer, always use of protective cloth, always use of hive stand, always use of langstroth hive, always use of bee brush, always use of honey extractor, always use of feeding with syrup, always use of foundation sheet, always use of queen cage and always use of queen excluder. The study focuses on cumulative adoption of the twelve components of technology. In this study, all of the twelve honey bees producing technology components were used for calculating the adoption index.

Adoption index was computed by adding the adoption score of each practice and dividing it by the number of technology component to know the level of adoption of each sample households. The score of component adoption was computed by giving a value of 2 for always user of technology component, 1 for some time user of technology component and 0 never used the technology component. Then the adoption index score ranges from 0 to 1 . The adoption index score 0 point implies non adoption of honey bee producing technology components. The adoption index score of 1 implies the respondents adopted all practices according to the recommendation. The final adoption index of sample adopter households were categorized into three adopter groups namely low, medium and high. The actual adoption index of this study was fall from 0 to 0.30 score range. 
Factors' influencing adoption and intensity of adoption of honey bee production was analyzed using a censored Tobit model. Adenisa and Zinnah (1993) underscore the benefit of Tobit Model weighing a lot over the Linear Probability. It has an advantage over other adoption models (Logistic, and Probit) in that it reveals both the probability of adoption and intensity of use of honey bee hive technology package. The model is also preferable than others during studying factors influencing adoption and intensity of adoption at a time (Greene, 2003).

\section{Model specification}

The econometric model applied for analyzing factors influencing adoption and intensity of adoption of honey bee hive technological package was the censored Tobit model shown in equation (1). Following Maddala (1992), Amemiya (1985) and Dandiro and Johnston (1997) the Tobit model for the continuous variable adoption index, can be defined as:

$A I^{*}=B O+B i X i+U i$

$\mathrm{AIi}=\mathrm{AI} i * \mathrm{if} \mathrm{BO}+\mathrm{BiXi}+\mathrm{Ui}>0$.

$=0$ if $\mathrm{BO}+\mathrm{BiXi}+\mathrm{Ui} \leq 0$

Where: AIi $=$ is adoption index for ith farmer

AIi* $=$ is the latent variable and the solution to utility maximization problem of intensity of adoption subjected to a set of constraints per household and conditional on being above certain limit,

$\mathrm{X}=$ Vector of factors affecting adoption and intensity of adoption,

$\mathrm{Bi}=$ Vector of unknown parameters, and

$\mathrm{Ui}=$ is the error term which is normally distributed with mean 0 and variance $\sigma 2$.

The model parameters are estimated by maximizing the Tobit likelihood function of the following form (Maddala, 1997 and Amemiya, 1985) (Table 2).

$\mathrm{L}=\prod_{\mathrm{AI}_{\mathrm{i}}^{*} *>0} \frac{1}{\sigma} \mathrm{f}\left(\frac{\mathrm{AI}_{\mathrm{i}}-\beta_{\mathrm{i}} \mathrm{X}_{\mathrm{i}}}{\sigma}\right) \prod_{\mathrm{AI}_{\mathrm{i}} * \leq 0} \mathrm{~F}\left(\frac{-\beta_{\mathrm{i}} \mathrm{X}_{\mathrm{i}}}{\sigma}\right)$

Where:

$f$ is the density function

$\mathrm{F}$ is cumulative distribution function of AIi*

$\Pi$

$A I_{i} \leq 0$ is the product over those $\mathrm{i}$ for which $\mathrm{AII} * \leq 0$, and

$\Pi$

$A I_{i}>0 \quad$ is the product over those $\mathrm{i}$ for which $\mathrm{AI} \mathrm{I}^{*}>0$.

Dandiro and Johnston (1997), proposed the following techniques to decompose the effects of explanatory variables into adoption and intensity effects. Thus, change in Xi (explanatory variables) has two effects. It affects the conditional mean of AI* in the positive part of the distribution, and it affects the probability that the observation will fall in that part of the distribution. Similarly, in this study, the marginal effect of explanatory variables was estimated as follows.

I. The marginal effect of an explanatory variable on the expected value of the dependent variable is: $\frac{\partial \mathrm{E}\left(A I_{i}\right)}{\partial X_{i}}=F(z) \beta i$ 
Where, $\frac{\beta_{i} X_{i}}{\sigma}$ is denoted by z, following Maddala, (1997)

II. The Change in the probability of adopting a technology as independent variable Xi changes is:

$$
\frac{\partial \mathrm{F}(\mathrm{Z})}{\partial \mathrm{X}_{\mathrm{i}}}=\mathrm{f}(\mathrm{Z}) \frac{\beta_{\mathrm{i}}}{\sigma}
$$

III. The change in the intensity of adoption with respect to a change in an explanatory variable among adopters is:

$$
\frac{\partial \mathrm{E}\left(\mathrm{AI}_{\mathrm{i}} / \mathrm{AIi}_{\mathrm{i}}^{*}>0\right)}{\partial \mathrm{X}_{\mathrm{i}}}=\beta_{\mathrm{i}}\left[1-\mathrm{Z} \frac{\mathrm{f}(\mathrm{z})}{\mathrm{F}(\mathrm{z})}-\left(\frac{\mathrm{f}(\mathrm{z})}{\mathrm{F}(\mathrm{z})}\right)^{2}\right]
$$

Where,

$F(z)$ is the cumulative normal distribution of $Z$,

$f(z)$ is the value of the derivative of the normal curve at a given point,

$Z$ is the $z$-score for the area under normal curve,

$\beta$ is a vector of Tobit maximum likelihood estimates and

$\sigma$ is the standard error of the error term.

Table 2. Description of explanatory variables used in the Censored Topit model.

\begin{tabular}{lll}
\hline Variables & Variables description & Expected relation \\
EDUCAHH & Education of household head in year of schooling & + \\
TLU & Total livestock holding in TLU & + \\
LANDHOLD & Household total land holding in hector & + \\
FARMINC & Average farm income measures in birr & + \\
EXTECONCT & Extension contact & + \\
TRAINMGT & Training on the management of bee & + \\
APVIST & Dummy, 1 if households visit Apiary site ; 0 otherwise & + \\
CREDITUSE & Access to credit use & - \\
MARKTDIST & Distance from market in kilometer & - \\
PRICPERC & Perceived cost of technology & + \\
KNLDBEMGT & knowledge of bee keeping management & + \\
AVAILTECH & Availability of beekeeping technology &
\end{tabular}

\section{Results and discussion}

\section{Current status of adoption and intensity of adoption of bee keeping technology}

New technologies/practices are usually recommended in a set or package form for use by farmers. However, for several reasons, farmers usually adopt only certain components of the package. Moreover, in most cases there is variation in intensity or level of use of a given technology or practice. Diversity among farmers in their level of package adoption could be related to many factors: economic, social, personal, institutional and psychological. Understanding why farmers adopt one component of the package while rejecting the other as well as the underlying reasons for their variation is of a paramount importance.

The survey results revealed that from the total sample respondents, $32 \%$ were non-adopter of beekeeping technology in the study area since their index was zero. From the total adopters category, about $19(9.5 \%)$ fall under low adopters' category, $89(44.5 \%)$ fall under medium adopters' category and $28(14 \%)$ respondents fall under high adopters' 
category. Moreover, the result indicates that the mean adoption index scores of non-adopters, low, medium and high adopters groups were $0.000,0.166,0.217$ and 0.300 , respectively. One way analysis of variance revealed that, there was significant mean difference $(F=2.401 \& P=000)$ among the adoption index scores of the four adopter categories at $1 \%$ significance level. Therefore, this implies that there was variation in level of adoption of beekeeping technology among sample farmers in study area (Table 3 ).

Table 3. Current status of adoption and intensity of adoption of bee keeping technology.

\begin{tabular}{|c|c|c|c|c|c|c|}
\hline $\begin{array}{l}\text { Adopter } \\
\text { Category }\end{array}$ & $\mathbf{N}$ & $\%$ & $\begin{array}{l}\text { Adoption index } \\
\text { Range }\end{array}$ & $\begin{array}{l}\text { Mean Adoption } \\
\text { index }\end{array}$ & SD & $\mathbf{F}$ \\
\hline Non adopters & 64 & 32 & 0.0 & 0.000 & 0.000 & \\
\hline Low adopters & 19 & 9.5 & $0.01-0.18$ & 0.166 & 0.010 & \\
\hline Medium ado. & 89 & 44.5 & $0.19-0.27$ & 0.217 & 0.024 & \\
\hline High adopters & 28 & 14 & $0.28-1.00$ & 0.300 & 0.022 & \\
\hline Total & 200 & 100 & $0-1$ & 0.171 & 0.014 & $2.401 * * *$ \\
\hline
\end{tabular}

Where *** indicates significant at $1 \%$ probability level.

\section{Econometric model results}

This part of the study indicates that factors affecting adoption and intensity of adoption of bee keeping technology in the study area. Censored Tobit model was used to see the relative influence of different personal, demographic, economic, institutional, and socio- psychological variables on adoption and intensity of adoption of honey bee hive technology. Tobit Model is appropriate to censored data and to know the influence of each variable determined based on the probability adoption and intensity of adoption of honey bee hive technology component (Dinardo and Johnston, 1997). Among the twelve explanatory variables were included in the model six variables were found to significantly influence adoption and intensity of adoption of honey bee hive technological package. These were Livestock (TLU), Apiary visit (APVIST), Market distance (MARKTDIST), Knowledge of bee keeping management (KNLDBEMGT), Availability of technology (AVAILTECH) and Perceived cost of technology (PRICPERC). Accordingly, the interpretation of this independent variables contribution for a tendency of changing adoption and intensity of adoption on honey bee hive technological components' of farmers at different levels of significance were discussed as follows

Livestock holding (TLU): It is one of the explanatory variables that influences adoption and intensity of adoption of honey bee hive technological package. TLU holding and adoption and intensity of adoption of bee keeping technology in this has positive and statistically significant correlation at $1 \%$ probability level. The result shows that a unit increase in tropical livestock unit has found to push farmers towards adopting honey bee hive technological package by $0.76 \%$, and the intensity of adoption will also favored by $0.94 \%$. This is plausible that TLU holding is important source of income push to adopt of honey bee hive technology for farm households since it is source of money for buying component of hive. Regarding relationship of livestock holding with adoption, many adoption studies so far conducted have also reported similar results. For instance Rahmeto (2007) and Geoffrey (2004) have found that livestock holding has positive and significant influence on adoption of improved agricultural technologies.

Apiary visit (APVIST): The results computed in the model indicated that as households visited apiary site elsewhere have better in the use of hive technology as compared to none visit households. Accordingly, as the household head visit apiary site elsewhere, the probability of adoption of hive technological package and use extent also increases by $8.5 \%$ and $11.5 \%$, respectively. It has been learned that when farmers visit elsewhere apiary site, the probability of intensity of adoption of hive increases at better statues.

Knowledge of bee keeping management (KNLDBEMGT): A change in knowledge of bee keeping management brings about 3.2\% increases of probability of adoption and $3.0 \%$ of intensity of use of honey bee hive technological package by the adopters. This is because as an individual who is aware about management of honey bee will gain some more understanding of bee keeping management. The result confirms the finding by Degnet and Belay (2001) and Rahmeto (2007). 
Market distance (MARKTDIST) (km): The further the distance to market the more the farmers are hindered from adopting new technologies. According to this finding, as distance away from the market by one kilometer, study farmers shown a tendency to decrease adoption and intensity of adoption of honey bee hive technological package by $0.69 \%$ and $1.23 \%$ respectively. This implies that, market distance is one of the determining factors in adoption of improved technology. Similar to this finding, the research result carried by Legesse et al. (2001) and Ebrahim (2006)) showed that distance to market and adoption and intensity of use of technologies found to be negative and significant relationship. This is plausible that, if farmers are closer and easily access to market, they can easily purchase hive components and sell the bee products without traveling long distances. Farmers also will be motivated to use hive technological components if they have access to market and for their output selling in good price.

Availability of technology (AVAILTECH): Availability of improved honey bee technological component to farmers is typically the major component of honey bee production improvement. According to the model result, a shift from technology unavailability to availability increases the probability of adoption and intensity of adoption of bee keeping package by $5.6 \%$ and $7.2 \%$ respectively. This implies that availability of hive technological component in the market promote adopting honey bee hive technological package. This finding is consistent with the findings of Berhanu (2002).

Perceived cost of technology (PRICPERC): This refers to respondents' perception about the cost of technological component of honey bee hive. Accordingly, the model result shows that a shift in perception of farmer on the price of component of bee keeping technology from very cheap to very expensive increase by $1.2 \%$ in probability of adoption and $1.37 \%$ in intensity of adoption of honey bee hive technological package (Table 4 ).

Table 4. Maximum likelihood estimates of Tobit Model.

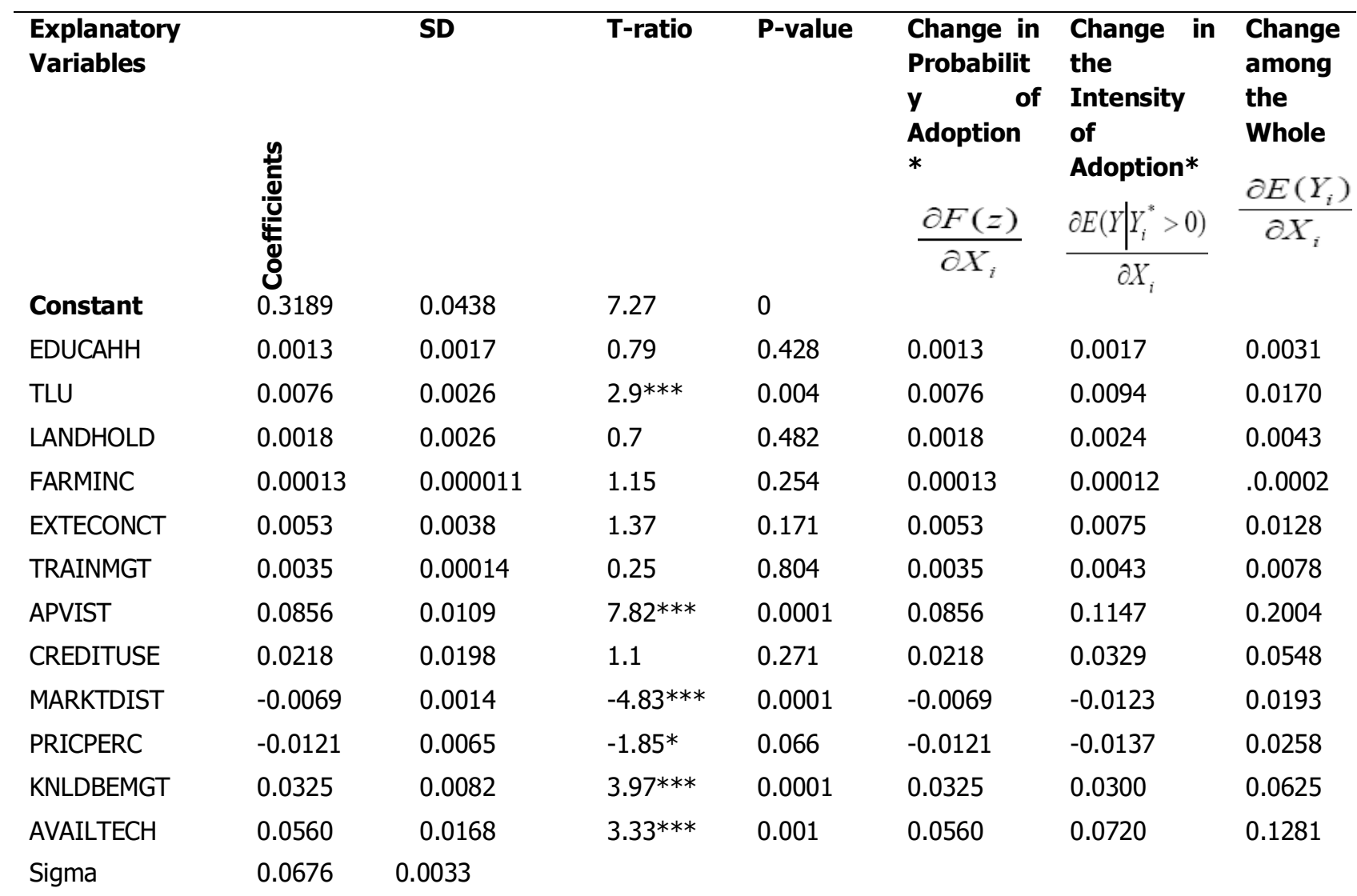

Log likelihood function $=-251.02$

Pseudo R2 $=-0.6792 \quad \mathrm{P}=.000$

Where $* * *$, and $* *$, represents $1 \%$ and $5 \%$ level of significance, respectively. 


\section{Conclusions and Recommendations}

Different bee keeping package practices were found to be used by bee keeper in this study area, but there was variation among the bee keeping households in the level of adoption or use of these practices. On the other hand, farmers' practices were found to deviate from farmers to farmers. The mean adoption index scores of non-adopters, low, medium and high adopters groups was $0.000,0.166,0.217$ and 0.300 , respectively with significant mean difference. The adoption index of sample households' reveals that from the total sampled household heads, about 64 (32\%) of them were found under non- adopter category and the remaining households were found under adopter category of bee keeping technology with different range of adoption.

From total of twelve (12) explanatory variables included in the Censored Tobit model six (6) of them had shown significant relationship with adoption and intensity of adoption of bee hive technological package. Accordingly, total livestock unit, apiary site visit by farmer, perceived cost of technology by farmer, knowledge of farmers for bee management and availability of bee hive technology were found to have positive and significant influence with adoption and intensity of adoption of bee hive technological package. However, distance of market center from home was found to have negative and significant relationship with adoption and intensity of adoption of bee hive technological package in agreement to the hypothesis.

Therefore, there should be institutional support in creating market linkage, infrastructural development, to enhance the production and productivity of poor farmer's in bee keeping, to demonstration site of apiaries to equip farmers with practical experience of transitional beekeeping methods under local conditions.

\section{Conflict of Interest}

The authors declare that they have no conflict of interest.

\section{Acknowledgments}

We thank Mizan-Tepi University for providing the research grant and facilitating the research work. Our gratitude also goes to the farmers of Sheko woreda for their collaboration to make available valuable information for completion of the study.

\section{References}

Adenisa, A. A., Zinnah, M. M., (1993). Technology characteristics, farmers' perceptions and adoption decision: A Tobit model application in Sierra Leone. American Journal of Agricultural Economics, 9, 297-311.

Akanbi, M. O. (1994). Non-wood Resources of Nigeria Rainforest. Honey Bee Management and Research.

Amemiya, T. (1985). Advanced Econometrics. T.J press, Padstow Ltd. Great Britain.

Asres, E. (2005). Access and Utilization of Development Communication by Rural Women in Dire Dawa Administrative Council, Eastern Ethiopia. An M.Sc Thesis Submitted to School of Graduate Studies of Haramaya University.

Belay, K., Degnet, A. (2004). Challenges facing Agricultural Extension agents: a case study from South-Western Ethiopia, African Development bank, published by Blackwell publishing Ltd, 139-168.

Berhnu, B. (2002). Analysis of factors affecting the Adoption of crossbred Dairy cows in the central Highlands of Ethiopia An M.Sc Thesis Submitted to School of Graduate Studies of Haramaya University.

BoA (2013). Annual report on the general conditions of Shoko Woreda, Bench Maji Zone Zone, Mizan Teferi.

Dinardo, J., Johnson, J. (1997). Econometric Methods. Fourth Edition. The McGraw Hill Companies, Inc, New York.

Fichtl, R., Admasu, A. (1994): Honeybee Flora of Ethiopia. MargrafVerlag, Germany, 43-50.

Geoffrey, N. (2004). Factors Affecting Smallholder Farmers' Adoption of Soil and Water Conservation Practice in Zambia.

M.Sc Thesis Presented to Michigan State University, 13-36.

Green, H. W. (2000). Econometric Analysis. Fourth Edition. New York University Macmillan Publishing Campany, 857-871

Legesse, D., Mulugeta, E., Belay, K. (2001). Determinants of Adoption of Soil Conservation Measures in Central Highlands of Ethiopia. The Case of Three s of North Shoa. Agrekon, 40, 3.

Maddala, G. S. (1997). Limited Dependent and Qualitative Variables in Econometrics. Cambridge University Press. MoARD (2007). Livestock Development Master Plan Study. Phase I Report - Data Collection and Analysis, Volume NApiculture. Addis Ababa, Ethiopia: Ministry of Agriculture \& Rural Development. 
Nicola, B. (2002). Taking the sting out of beekeeping. Arid Lands Information Network-East Africa (CD-Rom). Nairobi, Kenya.

Nuru, A. (2002). Geographical races of the Honey bees (Apis mellifera L.) of the Northern Regions of Ethiopia. PhD dissertation, Rhodes University, Department of Zoology and Entomology, South Africa, 265.

Rahmeto N, (2007). Determinants of Adoption of Improved Haricot Bean Production Package In Alaba Special Woreda, Southern Ethiopia. An M.Sc Thesis Submitted to School of Graduate Studies of Haramaya University.

Citation: Albore, A., Anshiso, D., Abraham, A. (2019). Adoption and Intensity of Adoption of Beekeeping Technology by Farmers: The Case of Sheko Woreda of Bench-Maji Zone, South West Ethiopia. Ukrainian Journal of Ecology, 9(3), 103-111

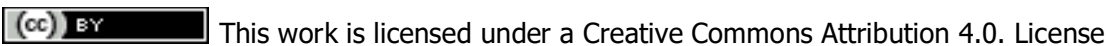

